\title{
In Situ Formation of Metal Hydrides Inside Carbon Aerogel Frameworks for Hydrogen Storage Applications
}

\author{
Mohammad Reza Ghaani ${ }^{1, *(\mathbb{C}}$, Mahdi Alam ${ }^{2}$, , Michele Catti $^{3}$ and Niall J. English ${ }^{1, *(1)}$ \\ 1 School of Chemical and Bioprocess Engineering, University College Dublin, Belfield, Dublin 4, Ireland \\ 2 Department of Civil and Environmental Engineering, K.N. Toosi University of Technology, Vali Asr Street, \\ Tehran 19967-15433, Iran; maalam@mail.kntu.ac.ir \\ 3 Dipartimento di Scienza Dei Materiali, Universita di Milano Bicocca, Via Cozzi 55, 20125 Milano, Italy; \\ michele.catti@unimib.it \\ * Correspondence: mohammad.ghaani@ucd.ie (M.R.G.); niall.english@ucd.ie (N.J.E.); \\ Tel.: +353-1-716-1758 (M.R.G.); +353-1-716-1646 (N.J.E.)
}

Received: 4 May 2020; Accepted: 2 June 2020; Published: 9 June 2020

\begin{abstract}
Nano-confined chemical reactions bear great promise for a wide range of important applications in the near-to-medium term, e.g., within the emerging area of chemical storage of renewable energy. To explore this important trend, in the present work, resorcinol-/formaldehydebased carbon aerogels were prepared by sol-gel polymerisation of resorcinol, with furfural catalysed by a sodium-carbonate solution using ambient-pressure drying. These aerogels were further carbonised in nitrogen to obtain their corresponding carbon aerogels. Through this study, the synthesis parameters were selected in a way to obtain minimum shrinkage during the drying step. The microstructure of the product was observed using Scanning Electron Microscopy (SEM) and Field Emission Scanning Electron Microscopy (FESEM) imaging techniques. The optimised carbon aerogels were found to have pore sizes of $\sim 21 \mathrm{~nm}$ with a specific accessible surface area equal to $854.0 \mathrm{~m}^{2} / \mathrm{g}$. Physical activation of the carbon aerogel with $\mathrm{CO}_{2}$ generates activated carbon aerogels with a surface area of $1756 \mathrm{~m}^{2} / \mathrm{g}$ and a total porosity volume up to $3.23 \mathrm{~cm}^{3} / \mathrm{g}$. The product was then used as a scaffold for magnesium/cobalt-hydride formation. At first, cobalt nanoparticles were formed inside the scaffold, by reducing the confined cobalt oxide, then $\mathrm{MgH}_{2}$ was synthesised as the second required component in the scaffold, by infiltrating the solution of dibutyl magnesium $\left(\mathrm{MgBu}_{2}\right)$ precursor, followed by a hydrogenation reaction. Further hydrogenation at higher temperature leads to the formation of $\mathrm{Mg}_{2} \mathrm{CoH}_{5}$. In situ synchrotron X-ray diffraction was employed to study the mechanism of hydride formation during the heating process.
\end{abstract}

Keywords: hydrogen storage; complex hydride; metal hydride; carbon aerogel; xerogel; response-surface methodology; magnesium cobalt hydride

\section{Introduction}

Hydrogen is very promising as a potential future carrier of renewable energy. However, it is an enormous challenge to develop compact, efficient, strong, safe, and low-cost hydrogen storage systems [1]. Hydrogen storage in the solid state seems to provide the best opportunities to accomplish all of these requirements. Consequently, a breakthrough in this field of knowledge can only be achieved by synthesising new active materials [2,3].

Reviewing the literature for chemical hydrogen storage applications reveals that metal hydrides and light metal borohydrides have been studied more in comparison to other approaches [1,4,5]. Ternary $\mathrm{Mg}_{2} \mathrm{CoH}_{5}$, featuring a high gravimetric and volumetric hydrogen density $\left(\sim 100 \mathrm{~kg} \mathrm{H}_{2} \mathrm{~m}^{-3}\right.$ and $4.5 \mathrm{wt} \%$, 
respectively), besides its relatively low cost and good sorption kinetics, is known as a good candidate for both stationary and portable applications [6]. $\mathrm{Mg}_{2} \mathrm{CoH}_{5}$ has been mainly synthesised by (i) direct sintering of $\mathrm{Mg}$ and $\mathrm{Co}$ at high temperature under high hydrogen pressures [7,8]; (ii) high-temperature, high-pressure sintering of a milled $2 \mathrm{Mg}$-Co powder mixture [9,10]; (iii) reactive mechanical milling of $\mathrm{Mg}$ and $\mathrm{Co}$ mixture under a hydrogen atmosphere [11,12]; and, (iv) mechanically mixing $2 \mathrm{MgH}_{2}-\mathrm{Co}$ in the presence of a hydrogen atmosphere at ambient pressure [13]. Direct ball-milling, starting from $\mathrm{MgH}_{2}$ and $\mathrm{Co}$, is found to be a better process in comparison to other approaches. This improvement reveals that having $\mathrm{MgH}_{2}$ in close contact with transition metals is an effective way of enhancing the kinetics of hydride formation. Unfortunately, the slow kinetics in hydrogen release/uptake has limited the use of metal hydrides. However, nanotechnology can present some novel concepts and solutions to the abovementioned issues [14,15], which will be addressed in the present study. Therefore, developing an effective confinement system at the nanoscale will hinge on the prohibition (or minimisation) of agglomeration and grain growth through uptake/release cycles.

Carbon aerogels (CA) provide a specific range of characteristics, such as continuous and tuneable porosity, ample surface area, considerable rate of conductivity chemical stability and low mass density [16]. These special properties make them a valuable group of new materials with great potential for an extensive variety of novel applications. Carbon aerogels can be synthesised using a template such as zeolites, silica, or some polymers to achieve a porous 3D nanostructured carbon with controlled porosity. The host materials can be removed during or after the final heat-treatment step $[17,18]$. Another typical method is pyrolysis of a solid organic aerogel, followed by sol-gel polycondensation of different organic monomers such as resorcinol, formaldehyde, phenol, and others. It is possible to control the pore size and structure of the produced carbon aerogels tailoring the synthesis conditions, such as $\mathrm{pH}$, sol composition, pyrolysis temperature, etc. [16]. In this context, a drying method-applied for extracting water from the initial gel structure-is used to categorise carbon gels. Indeed, the water-extraction method has a crucial effect on the final 3D structure of the aerogel: it affects the pore volume, pore type and total specific surface area of the sample. Water extraction via supercritical drying, freeze-drying, or ambient pressure drying can serve to form Carbon Aerogels, Carbon Cryogels and Carbon Xerogels [19]. Importantly, Carbon Xerogel does not need specific and expensive drying equipment, since it is dried at ambient pressure and temperature conditions, while this is not possible for the other two carbon gels. As such, the application of Carbon Xerogel is considerably more economic, and operationally efficient. This economic benefit is related to lowering the expense of realizing a target shrinkage rate during gel formation, allowing for desiderata, such as reduced porosity and a higher final specific surface area.

Bearing this background in mind, the central goal of the present study is to minimise the degree of shrinkage whilst keeping the cost efficiency and simplicity of the process. To this end, the first step will be to prepare an organic with controlled physical and chemical properties. Indeed, numerous factors can be 'tuned' during the synthesis process-with some factors changing considerably the quality of the final gel. These include, inter alia: catalyst type, $\mathrm{pH}$ of the initial RFC solution, the molar ratio of Resorcinol/Catalyst (R/C), the molar ratio of Resorcinol/Formaldehyde, the mass ratio of reactant/liquid, gelation time and temperature, solvent replacement, the drying and pyrolysis processes' temperature and time. Previous studies have revealed that the ratio of reactant/liquid, $\mathrm{pH}$ of the initial solution, and pyrolysis temperature significantly affect the final properties of the gel $[16,19,20]$.

Formaldehyde plays an important role in the cross-linking of resorcinol molecules, and to have a properly formed solid gel, the molar ratio of resorcinol/formaldehyde $(\mathrm{R} / \mathrm{F})$ is suggested to be in the range of 0.4-0.7 [21]. High residual unreacted formaldehyde will collapse the 3D structure of the gel. On the other hand, any shortage of cross-linker (formaldehyde) will impede the development of a proper gel with a high level of cross-linked aromatic molecules [22]. Raising the amount of catalyst leads to a significant decrease in the length of starting gel polymers, and an increase in the velocity of gelation [23]. 
In the present study, we evaluate the observed shrinkage during the gelation process of prepared Carbon Xerogel catalysed by $\mathrm{Na}_{2} \mathrm{CO}_{3}$. To do so, we study the effect on the shrinkage of the synthesised Carbon Xerogel, through response surface methodology with Box-Behnken experimental design, of (i) the $\mathrm{pH}$ of the initial sol, (ii) the mass ratio of Reactants/Liquid (R/L), and (iii) the Pyrolysis Temperature (PT).

This study was done in three stages: (1) the optimisation of the carbon xerogel synthesis condition, (2) the infiltration of the starting reagents into the optimised xerogel and (3) the in situ synthesis of $\mathrm{Mg}_{2} \mathrm{CoH}_{5}$. Response surface methodology (RSM) was employed to find the optimum synthesis route. Using the synthesis methods presented in our previous paper [24], we synthesised cobalt nanoparticles inside our optimised carbon xerogel. Infiltration of Di-n-butylmagnesium provides the required reagents for the in situ formation of $\mathrm{Mg}_{2} \mathrm{CoH}_{5}$. This study investigates the mechanism of the formation of ternary $\mathrm{Mg}_{2} \mathrm{CoH}_{5}$ inside carbon xerogel following its X-ray diffraction pattern. In addition, the experimental results are verified through morphological and microstructural investigations conducted using SEM, FESEM, Brunauer-Emmett-Teller (BET) surface area analysis and ICP techniques.

\section{Materials and Methods}

There are different "experimental design" methodologies, amongst which the Box-Behnken Design (BBD) in response surface methodology (RSM) is the best fitted to our purposes, in that it has a low number of levels in parameter for efficient parameter search/exploration. Here, the BBD design for $\mathrm{pH}, \mathrm{R} / \mathrm{L}$ and PT combined with three Centre-Point replicas, suggested a set of 15 experiments (Table 1). In this design, the ratio between Resorcinol to Formaldehyde is constant and equal to 0.5.

Table 1. Set of designed experiments according to BBD design.

\begin{tabular}{cccc}
\hline Run No. & Reactants/Solution $(\%)$ & $\mathbf{p H}$ & Pyrolysis Temperature $\left({ }^{\circ} \mathbf{C}\right)$ \\
\hline 1 & 35 & 5.5 & 900 \\
2 & 35 & 5.5 & 600 \\
3 & 50 & 5.5 & 750 \\
4 & 30 & 5.5 & 750 \\
5 & 35 & 6.25 & 750 \\
6 & 30 & 6.25 & 900 \\
7 & 35 & 6.25 & 750 \\
8 & 50 & 6.25 & 900 \\
9 & 30 & 6.25 & 600 \\
10 & 50 & 6.25 & 600 \\
11 & 35 & 6.25 & 750 \\
12 & 35 & 7 & 600 \\
13 & 20 & 7 & 750 \\
14 & 50 & 7 & 750 \\
15 & 35 & 7 & 900 \\
\hline
\end{tabular}

A selected amount of resorcinol (99\%, Aldrich, St. Louis, MO, USA), formaldehyde in water (37 wt \% stabilised by 10-15\% methanol, Aldrich, St. Louis, MO, USA), and $\mathrm{Na}_{2} \mathrm{CO}_{3}$ (99.999\%, Aldrich, St. Louis, MO, USA) as catalyst were dissolved in deionised water. For each run, the sol was prepared by considering the specified Reactant/Solution and $\mathrm{pH}$ values (Table 1). The solutions were transferred to a silicon mould (Figure 1a), sealed in a chamber to avoid any solvent evaporation during gelation (Figure 1b). The gelation process was done in three distinct steps: (i) one day at $23{ }^{\circ} \mathrm{C}$ (ii) one day at $50{ }^{\circ} \mathrm{C}$, and (iii) three days at $90{ }^{\circ} \mathrm{C}$. The formed disk-shaped gels removed from the mould were cooled down to room temperature and immersed in acetone for solvent replacement (Figure 1c). The acetone bath was renewed every day to minimize the residual water. After three days of solvent exchange, the specimens loaded in a tube furnace and heated (with $2{ }^{\circ} \mathrm{C} \mathrm{min}^{-1} \mathrm{rate}$ ) to the suggested pyrolysis temperature under the flow of nitrogen, and maintained at that temperature for $6 \mathrm{~h}$ for a 
full pyrolysis process (Figure 1d). A 4-h activation process was carried out on the selected sample with the lowest shrinkage at $900{ }^{\circ} \mathrm{C}$ under a continuous flow of $\mathrm{CO}_{2}$. SEM/FESEM imaging techniques were employed to study the morphology of the product, and the surface area and pore volume of the synthesised xerogels were evaluated using BET technique, based on the Ar adsorption isotherm at liquid nitrogen temperature.

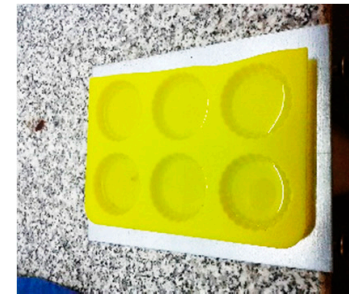

(a)

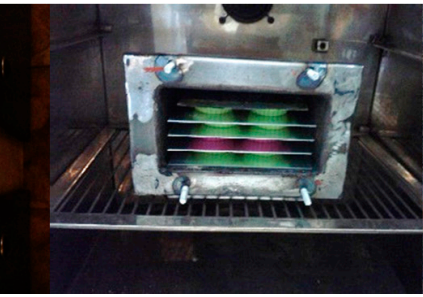

(b)

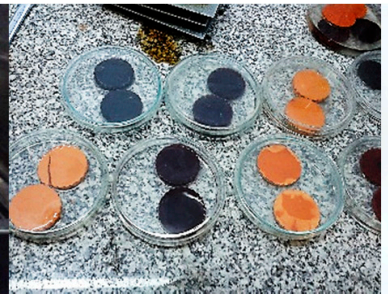

(c)

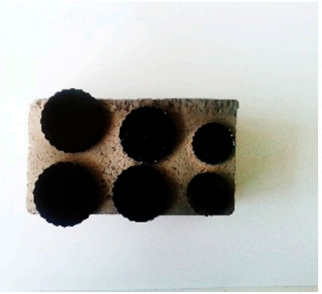

(d)

Figure 1. The experimental setup used for xerogel preparation: (a) silicon mould to keep all the disks in the same shape, (b) sealed chamber to avoid any solvent loss during the gelation process, (c) solvent exchange process, (d) different levels of shrinkage for carbon xerogels after pyrolysis.

The activated xerogel was selected for the confinement process. Impregnation of cobalt was carried out by an overnight immersing $0.5 \mathrm{~g}$ carbon xerogel in a 1-M $\mathrm{Co}\left(\mathrm{NO}_{3}\right)_{2} \cdot 6 \mathrm{H}_{2} \mathrm{O}$ solution in deionised water. The infiltrated gels were transferred to an autoclave to dry and nitrate decompose to form metal oxide, while heating the autoclave to $400^{\circ} \mathrm{C}$ under vacuum. To reduce the formed oxide to pure metal, the autoclave was loaded with 100 bar of hydrogen, heated up to $500{ }^{\circ} \mathrm{C}$ and left at that temperature for $8 \mathrm{~h}$. To add magnesium precursor to the cobalt-decorated carbon xerogel, the gel was immersed into 1.0-M Di-n-butylmagnesium $\left(\mathrm{Mg}(\mathrm{BU})_{2}\right)$ in heptane (Aldrich, St. Louis, MO, USA) overnight. The same process was repeated by $3.0-\mathrm{M} \mathrm{Mg}(\mathrm{BU})_{2}$ that was produced using commercial 1.0-M Mg(BU $)_{2}$, by evaporating the solvent (heptane) to reduce its volume to one third. All of the processes were handled inside a glovebox to avoid any contact with oxygen or water. To remove the non-confined reagent, which remained on the surface of the xerogel, scratching on abrasive paper (1000 girt) was used. The amount of compound uptake was evaluated using Spectro Arcos model ICP-OES (Thermo Fisher Scientific, Waltham, MA, USA).

In situ synchrotron radiation powder X-ray diffraction (SRPXD) experiments were done at DESY, Hamburg (P02.1 beamline- PETRA III) [25]. The infiltrated sample was ground and loaded into a sapphire capillary. The tube was assembled to the main sample holder. To start the experiment, 100 bar of hydrogen applied to the sample and temperature raised to $400{ }^{\circ} \mathrm{C}$ with $10{ }^{\circ} \mathrm{C} \mathrm{min}-1$ heating rate. To track the phase transition as a function of temperature, the temperature corresponding to each diffraction pattern was also measured using an internal thermocouple, in contact with the powder. Figure 2 shows a schematic of the sample holder [26].

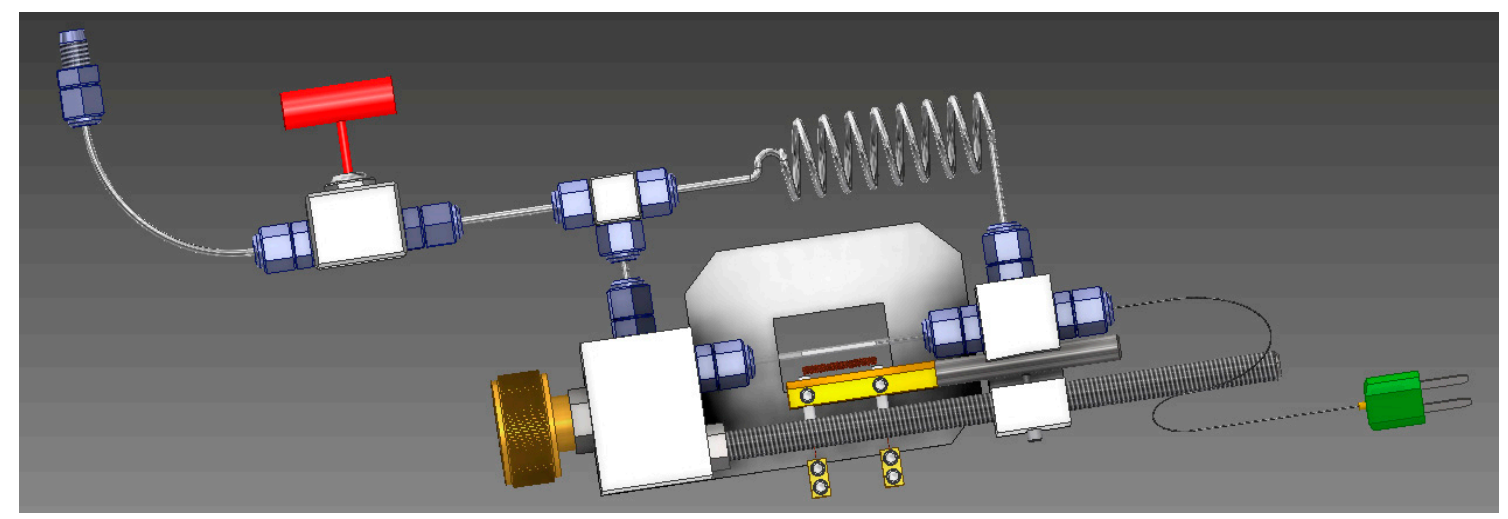

Figure 2. High-pressure sample holder used for in situ synchrotron data collection. 


\section{Results and Discussion}

The suggested experiments in the framework of the BBD design (Table 1) were conducted, and the final percentage of the shrinkage was compared with the formed disk after gelation was considered as the response measure. According to RSM design, a 2nd-order algebraic equation can be fitted to our results. RSM gives the following full quadratic model, where $\mathrm{Y}$ is the response (total shrinkage after pyrolysis). $\beta_{0}, \beta_{i}, \beta_{i i}$ and $\beta_{i j}$, are intercept constant, linear, quadratic and interaction parameters' coefficients, respectively-see Equation (1). K denotes to the number of design parameters and $\varepsilon$ represents the random-error residual associated with the experiments. This model returns an understanding of the impact of each variable and their mutual interactions on the objective response:

$$
Y=\beta_{0}+\sum_{i=1}^{k} \beta_{i} X_{i}+\sum_{i=1}^{k} \beta_{i i} X_{i}^{2}+\sum_{i=1}^{k} \sum_{j=i+1}^{k} \beta_{i j} X_{i} X_{j}+\varepsilon
$$

To determine the quality of the fitted model, an Analysis of Variance (ANOVA) was performed (Table 2). As a result, only two linear components of the fitted equation have a statistically significant effect on the final response parameter (Table 2) — concerning the calculated $p$-Values $\mathrm{pH}$ and PT had over $95 \%$ confidence thresholds. This means any change in $\mathrm{pH}$ and $\mathrm{PT}$ during the synthesis process will cause a different shrinkage, while if R/L changes in the range of $20 \%$ to $40 \%$, the final volume will not vary significantly.

Table 2. ANOVA table of RSM represented a model for the final shrinkage.

\begin{tabular}{|c|c|c|c|c|c|}
\hline Source & DF & Adj SS & Adj MS & $F$-Value & $p$-Value \\
\hline Model & 8 & 465.142 & 58.143 & 13.15 & 0.043 \\
\hline Linear & 3 & 343.015 & 114.338 & 25.86 & 0.037 \\
\hline $\mathrm{pH}$ & 1 & 222.606 & 222.606 & 50.35 & 0.019 \\
\hline $\mathrm{R} / \mathrm{L}$ & 1 & 9.738 & 9.738 & 2.20 & 0.276 \\
\hline PT & 1 & 110.670 & 110.670 & 25.03 & 0.038 \\
\hline Square & 2 & 12.818 & 6.409 & 1.45 & 0.408 \\
\hline $\mathrm{pH} \times \mathrm{pH}$ & 1 & 10.842 & 10.842 & 2.45 & 0.258 \\
\hline $\mathrm{PT} \times \mathrm{PT}$ & 1 & 4.940 & 4.940 & 1.12 & 0.401 \\
\hline $\begin{array}{l}\text { Two-Way } \\
\text { Interaction }\end{array}$ & 3 & 12.377 & 4.126 & 0.93 & 0.555 \\
\hline $\mathrm{pH} \times \mathrm{R} / \mathrm{L}$ & 1 & 7.207 & 7.207 & 1.63 & 0.330 \\
\hline $\mathrm{pH} \times \mathrm{PT}$ & 1 & 5.108 & 5.108 & 1.16 & 0.395 \\
\hline $\mathrm{R} / \mathrm{L} \times \mathrm{PT}$ & 1 & 0.062 & 0.062 & 0.01 & 0.917 \\
\hline Error & 2 & 8.843 & 4.421 & & \\
\hline Total & 10 & 473.984 & & & \\
\hline
\end{tabular}

The main effect of each parameter is also presented in Figure 3a; a decrease in the pH or PT results in decreasing the degree of final shrinkage of the xerogel. In essence, studying Figure 3 and Table 2 further, i.e., the contour plot derived from the proposed fitted equation (Figure $3 b$ ), the final shrinkage of a carbon xerogel can be predicted based on the two significant synthesis parameters ( $\mathrm{pH}$ and the pyrolysis temperature). With an $\mathrm{R} / \mathrm{L}$ equal to $35 \%$, the minimum shrinkage will be obtained in the corner of the studied PT and pH area. Therefore, by choosing PT in the range of 600-700 ${ }^{\circ} \mathrm{C}$ and $\mathrm{pH}$ between 5.5-5.7, a structure with very low degree of shrinkage can be obtained-see Figure $3 \mathrm{~b}$. The proposed global minimum of the final shrinkage was already tested as run number two, with $33.23 \%$ shrinkage at $\mathrm{pH}=5.5, \mathrm{R} / \mathrm{L}=35 \%$ and $\mathrm{PT}=600{ }^{\circ} \mathrm{C}$. 


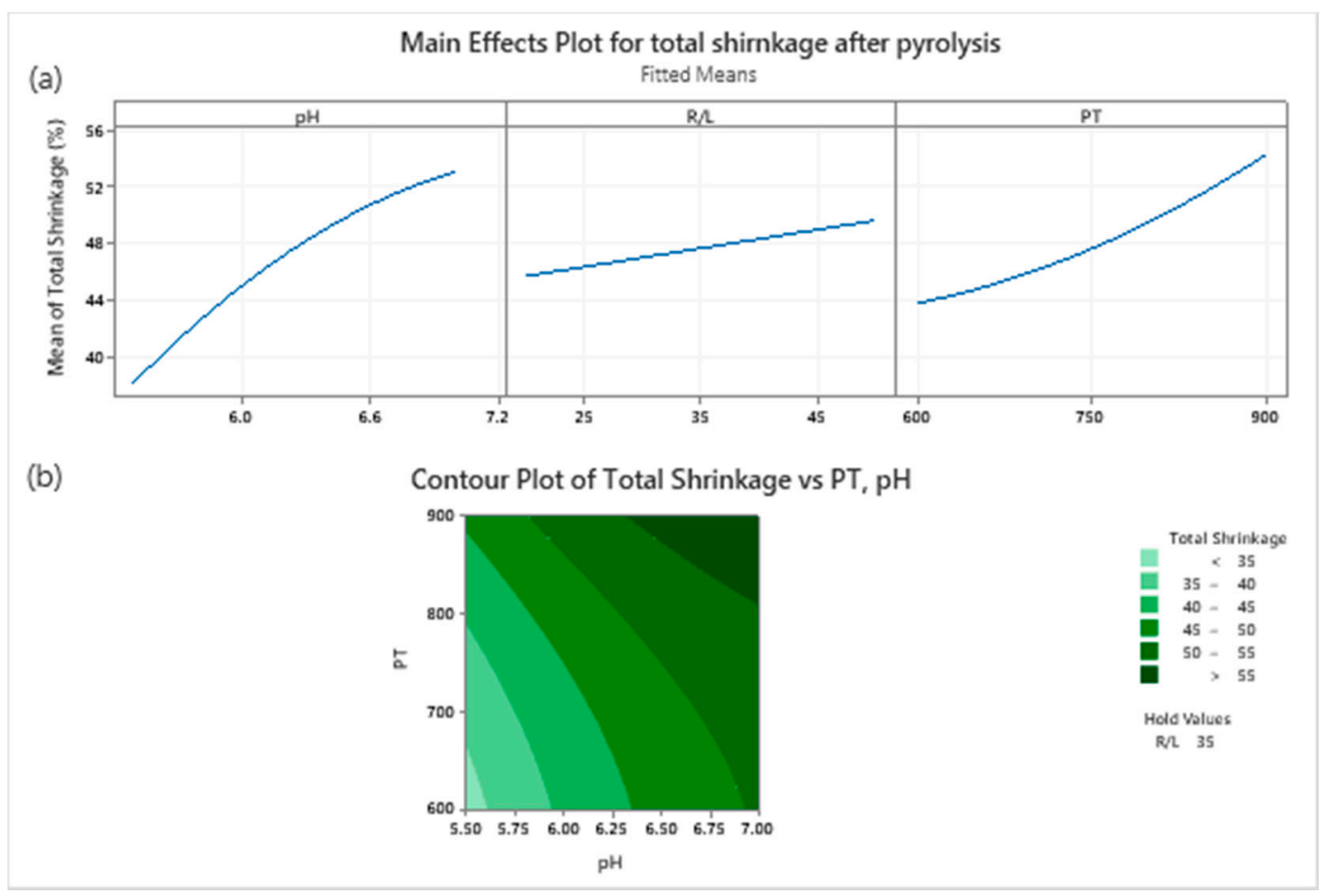

Figure 3. RSM main effect (a) and contour plots (b) for the total shrinkage of the carbon xerogel.

The morphological structure of the synthesised carbon xerogels was evaluated by different electron microscopy techniques. To glean a first impression on the effect of shrinkage on the microstructure of the specimen, the SEM images of the samples with highest (Figure 4a) and lowest (Figure 4b) shrinkage during the formation process (sample numbers 15 and 2, respectively) are presented. Severe shrinkage in sample number 15 leads to the formation of a dense structure with very low porosity, whilst for number two, a uniform pore distribution with a complex hierarchical porosity can be formed upon synthesis, with minimum shrinkage.

Activated carbon xerogel was also examined by field emission SEM. The high-resolution FESEM image presents a closer view of the carbon matrix which seems to be made of laminae of certain graphite-like layers in an 'onion-like' assembly. The 2D structure of graphite-like structures (Figure 4c) has a superior location to trap precursor molecules between its layers. Moreover, due to its high thermal conductivity, this location will serve as a preferential point for the nucleation of nanoparticles formed through a chemical reaction [27]. On the other hand, its geometry will (i) enhance the stability of the composite by securing the position of the confined nanoparticles, and (ii) prevent agglomeration of nanoparticle through multiple chemical reactions, which will enhance the cyclability behaviour of the composite [28]. Moreover, the high thermal conductivity of graphite-like structures will render this structure a good candidate for hydrogen storage applications, where its elevated heat-transfer properties will enhance the kinetics of hydrogen uptake/release in storage tanks [29]. 


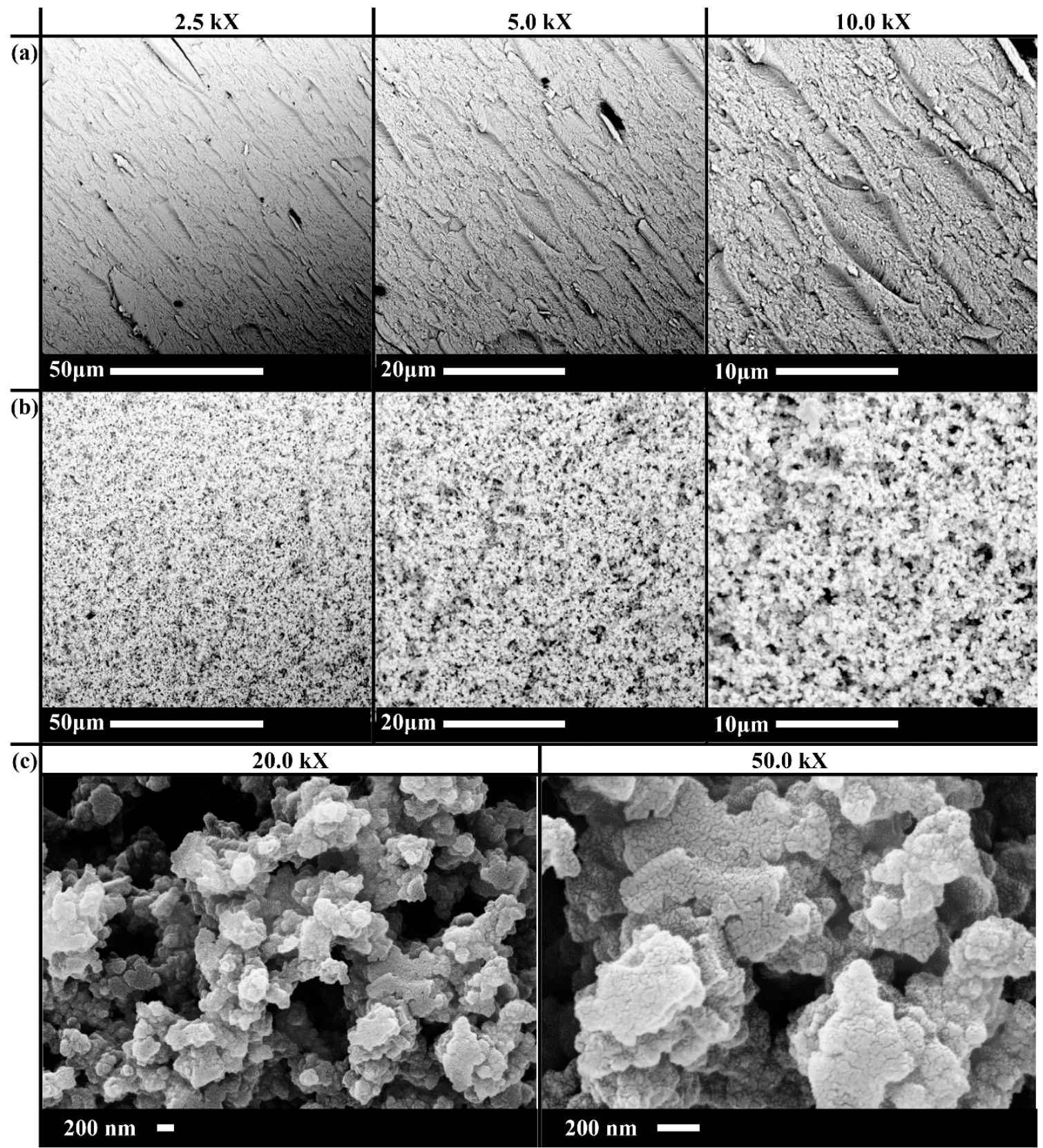

Figure 4. (a) SEM images of the product with maximum shrinkage (sample number 15) (b) SEM images of the product with minimum shrinkage (sample number 2). (c) FESEM images of the activated carbon xerogel at different zoom levels.

The microstructure properties of the optimised carbon xerogels, before and after the activation process, is reported in Table 3. As a result of carbon xerogel activation, a sample with almost the same pore diameter, but a larger specific surface area, was obtained. This observation was in agreement with the result reported by Contreras et al. [30].

Table 3. BET values of the optimised carbon xerogels before and after activation.

\begin{tabular}{cccccc}
\hline Sample Name & $\mathbf{S B E T}\left(\mathrm{m}^{2} / \mathbf{g}\right)$ & $\mathbf{V}_{\text {micro }}(\mathrm{cc} / \mathrm{g})$ & $\mathbf{V}_{\text {meso }}(\mathrm{cc} / \mathrm{g})$ & $\mathbf{D}_{\text {max }}(\mathbf{n m})$ & $\mathbf{V}_{\text {tot }}(\mathbf{c c} / \mathbf{g})$ \\
\hline Sample no. 2 & 854 & 0.226 & 1.51 & 21 & 1.73 \\
Sample no. 2-ACT & 1756 & 0.582 & 2.75 & 20 & 3.23 \\
\hline
\end{tabular}


ICP analysis revealed the number of different substances uptaken. In the case of $1 \mathrm{M}$ cobalt nitrate, $0.34 \mathrm{mmol} / \mathrm{g}$ gel was infiltrated, while the amount of magnesium in 1 and $3 \mathrm{M}$ Di-n-butylmagnesium is 0.98 and $0.91 \mathrm{mmol} / \mathrm{g}$ gel. Although the concentration of the precursor solutions was the same, the amount of confined magnesium is around three times higher than the cobalt uptake. The difference is due to a different characteristics of the main solutions, while Magnesium is introduced by organic solution and cobalt is present in an aqueous solution. This can be due to the hydrophobic nature of RF carbon xerogel [31] which will cause lower wettability followed by a lower capillary pressure for uptake in the case of aqueous solutions.

The phase evolution as a function of temperature is shown in Figure 5a. The starting structure, in addition to the peaks, belong to n-butylmagnesium; two polymorphs of cobalt are also present, one hexagonal [32] and one cubic [33] form of the Co. These two structures were formed during the indirect reduction of the infiltrated cobalt nitrate, as discussed earlier in the Materials and Methods section. The mechanism of this transition was studied in detail by Ghaani et al. [24]. Direct conversion of $\mathrm{Mg}(\mathrm{Bu})_{2}$ into $\mathrm{MgH}_{2}$ completed at about $180{ }^{\circ} \mathrm{C}$ (Figure 5a-red area) according to the following reaction, in Equation (2):

$$
\mathrm{Mg}\left(\mathrm{C}_{4} \mathrm{H}_{9}\right)_{2}(\mathrm{~s})+2 \mathrm{H}_{2}(\mathrm{~g}) \rightarrow \mathrm{MgH}_{2}(\mathrm{~s})+2 \mathrm{C}_{4} \mathrm{H}_{10}(\mathrm{~g})
$$

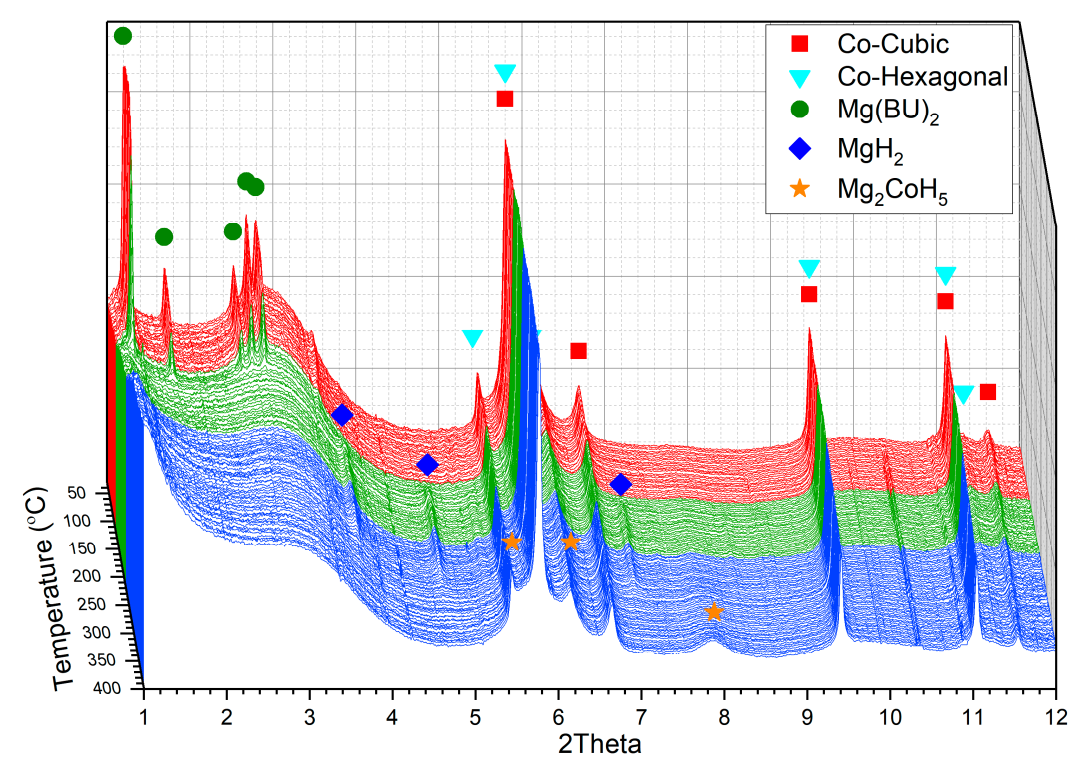

(a)

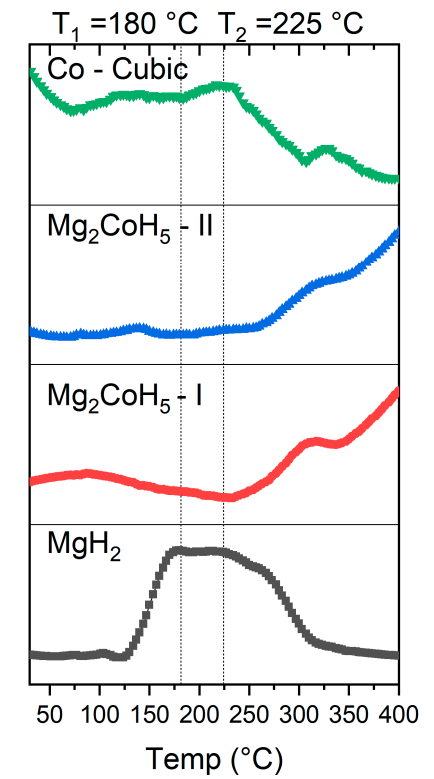

(b)

Figure 5. (a) In situ synchrotron $X R D$ patterns of a carbon xerogel infiltrated with $\mathrm{Co}+\mathrm{Mg}(\mathrm{Bu})_{2}$

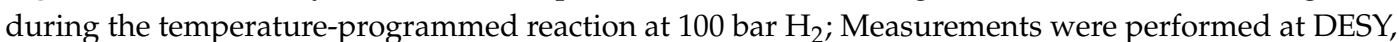
Hamburg $(\lambda=0.2072 \AA)$. (b) Standardised scale factors of $\mathrm{MgH}_{2}\left(2 \theta=7.01^{\circ}\right), \mathrm{Mg}_{2} \mathrm{CoH}_{5}\left(2 \theta=5.49^{\circ}\right.$ \& $\left.7.83^{\circ}\right)$ and Co-cubic $\left(2 \theta=11.59^{\circ}\right)$ as a function of temperature. Data were obtained from sequential Lorentzian peak fit of the in situ diffraction pattern.

The formed $\mathrm{MgH}_{2}$ is stable up to $225{ }^{\circ} \mathrm{C}$ (Figure 5a-green area), and at higher temperatures the peaks of magnesium hydride disappear (Figure $5 \mathrm{a}$-blue area), and $\mathrm{Mg}_{2} \mathrm{CoH}_{5}$ forms through the $\mathrm{Co}+\mathrm{MgH}_{2} \rightarrow \mathrm{Mg}_{2} \mathrm{CoH}_{5}$ reaction [34,35]. Low levels of crystallinity, alongside high XRD background levels due to the nature of the amorphous carbon scaffold, coupled with the overall complexity of the system, rendered tracking all of the phase transitions in these nano-confined systems difficult. The particles form inside the aerogel nanopores, resulting in in broadened diffraction peaks (featuring, ipso facto, large FWHM). Since there are very many randomly oriented grains (crystallites) in the bulk of these nanoparticles, it is was exceedingly difficult to ascertain a certain direction of crystallisation or ordered crystallographic planes in any one specimen of these samples; in this sense, one may consider 
many of these samples as exhibiting lower levels of overall, aggregate crystallinity. To address these challenges and track the formed phases more accurately, the area below the peaks with minimum overlap with other phases was calculated, and this is shown in Figure $5 \mathrm{~b}$.

At $255^{\circ} \mathrm{C}$, occurring simultaneously with consumption of the $\mathrm{MgH}_{2}$ and cubic cobalt, two peaks of $\mathrm{Mg}_{2} \mathrm{CoH}_{5}$ with cubic structure [8] appear at $2 \theta=5.49^{\circ}$ and $7.83^{\circ}$. This observation proves unambiguously the in situ formation of the nano-confined $\mathrm{Mg}_{2} \mathrm{CoH}_{5}$ inside the carbon xerogel's scaffold structure.

\section{Conclusions}

Given the overriding objective of obtaining and leveraging high-performance 3D porous carbon structures, whilst maintaining simplicity and low cost in its synthesis route, we have investigated-and realised successfully - the in situ formation of a complex hydride inside this optimised carbon xerogel porous scaffold-'hosting' material. In the first stage, the host was optimised through multi-parameter optimisation to minimise the carbon xerogel shrinkage during its formation. We studied the effect of $\mathrm{pH}, \mathrm{R} / \mathrm{L}$ and PT on the structure of the final carbon xerogel. It was found that the level of R/L does not have a significant effect on the final shrinkage of the formed structure of the xerogel. We showed that minimum shrinkage (33.23\%) can be obtained through a synthesis process with $\mathrm{R} / \mathrm{L}=35 \%$ and $\mathrm{PT}=600^{\circ} \mathrm{C}$ at $\mathrm{pH}=5.5$.

During the second stage, during two discrete steps, cobalt nitrate and Di-n-butylmagnesium as the elemental cobalt and magnesium precursors required for the formation $\mathrm{Mg}_{2} \mathrm{CoH}_{5}$ were infiltrated into the optimised carbon xerogel. Perhaps unsurprisingly, it was found that the uptake of an organic-based compound is significantly higher than aqueous-based reagents due to the hydrophobic nature of the carbon xerogel and lower capillary pressure inside the scaffold pores in the case of aqueous systems.

During the third stage, $\mathrm{MgH}_{2}$ formed through the reaction of $\mathrm{Mg}(\mathrm{BU})_{2}$ with hydrogen at about $150{ }^{\circ} \mathrm{C}$; at $225^{\circ} \mathrm{C}$, it will react with previously infiltrated cobalt nanoparticles to form $\mathrm{Mg}_{2} \mathrm{CoH}_{5}$. The mechanism of the formation of ternary $\mathrm{Mg}_{2} \mathrm{CoH}_{5}$ was investigated by studying the phase transition as a function time. The formed composite can be used in hydrogen storage applications as a compound exhibiting high gravimetric and volumetric hydrogen capacity and very promising 'cyclability' properties. For future work, a larger quantity of the sample needs to be prepared for a more accurate investigation on hydrogenation/dehydrogenation kinetics, and also a careful characterization of the cyclability and longer-term resilience of the formed composite. These results will be very helpful in showcasing the characteristics and advantages, and any possible drawbacks, of this most promising composite material, to afford a comprehensive comparative analysis vis-à-vis other more well-developed hydrogen storage materials.

It may be the case that molecular simulation [36]—especially in its guise of Density Functional Theory (DFT) — can deal with complicated chemical reactions in disparate electronic milieu of different atomistic environments of hydrides in heterogeneous scaffold environments; indeed, this may be able to optimise further materials design and selection. However, the appropriate selection and careful benchmarking and tailoring of DFT functionals in interfacial systems [37] will be very important in this vein, to ensure the highest quality of interatomic interactions, as well as in molecular simulation handling the wider challenge of handling possible hydrogen bonding accurately [38], which may well be important in some promising classes of hydrogen storage materials.

Author Contributions: M.R.G., M.A., M.C. and N.J.E. conceived the study conceptually. M.R.G. and M.A. designed and built the synthesis setup. M.R.G. and M.A. carried out the aerogel formation experiments, as well as characterisations. M.C. contributed importantly with an interpretation of results and crystallographic mechanisms. N.J.E. contributed importantly to the experimental design and statistical analysis. All authors have read and agreed to the published version of the manuscript.

Funding: This research received no external funding. 
Acknowledgments: M.R.G. wishes to express his thanks to Torben R. Jensen for his hosting and support. We acknowledge DESY (Hamburg, Germany), a member of the Helmholtz Association HGF, for the provision of experimental facilities. Parts of this research were carried out at PETRA III and we would like to thank Ann-Christin Dippel for assistance in using photon beamline.

Conflicts of Interest: The authors declare no conflict of interest.

\section{References}

1. Schlapbach, L.; Züttel, A. Hydrogen-storage materials for mobile applications. Nature 2001, 414, $353-358$. [CrossRef] [PubMed]

2. Felderhoff, M.; Weidenthaler, C.; Von Helmolt, R.; Eberle, U. Hydrogen storage: The remaining scientific and technological challenges. Phys. Chem. Chem. Phys. 2007, 9, 2643. [CrossRef] [PubMed]

3. Belosludov, R.; Bozhko, Y.; Zhdanov, R.; Subbotin, O.S.; Kawazoe, Y.; Belosludov, V.R. Hydrogen hydrates: Equation of state and self-preservation effect. Fluid Phase Equilibria 2016, 413, 220-228. [CrossRef]

4. Catti, M.; Ghaani, M.R.; Pinus, I. Overpressure Role in Isothermal Kinetics of $\mathrm{H}_{2}$ Desorption-Absorption: The $2 \mathrm{LiBH}_{4}-\mathrm{Mg}_{2} \mathrm{FeH}_{6}$ System. J. Phys. Chem. C 2013, 117, 26460-26465. [CrossRef]

5. Ghaani, M.R.; Catti, M.; Nale, A. Thermodynamics of Dehydrogenation of the $2 \mathrm{LiBH}_{4}-\mathrm{Mg}_{2} \mathrm{FeH}_{6}$ Composite. J. Phys. Chem. C 2012, 116, 26694-26699. [CrossRef]

6. Reiser, A. The application of Mg-based metal-hydrides as heat energy storage systems. Int. J. Hydrogen Energy 2000, 25, 425-430. [CrossRef]

7. Cerny, R.; Bonhomme, F.; Yvon, K.; Fischer, P.; Zolliker, P.; Cox, D.; Hewat, A. Hexamagnesium dicobalt undecadeuteride $\mathrm{Mg}_{6} \mathrm{Co}_{2} \mathrm{D}_{11}$ : Containing [CoD4]5- and [CoD5]4- complex anions conforming to the 18-electron rule. J. Alloys Compd. 1992, 187, 233-241. [CrossRef]

8. Zolliker, P.; Yvon, K.; Fischer, P.; Schefer, J. Dimagnesium cobalt(I) pentahydride, $\mathrm{Mg}_{2} \mathrm{CoH}_{5}$, containing square-pyramidal pentahydrocobaltate(4-) $\left(\mathrm{CoH}_{5}^{4-}\right)$ anions. Inorg. Chem. 1985, 24, 4177-4180. [CrossRef]

9. Fernández, I.G.; Meyer, G.; Gennari, F. Reversible hydrogen storage in $\mathrm{Mg}_{2} \mathrm{CoH}_{5}$ prepared by a combined milling-sintering procedure. J. Alloys Compd. 2007, 446, 106-109. [CrossRef]

10. Fernández, I.G.; Gennari, F.; Meyer, G. Influence of sintering parameters on formation of Mg-Co hydrides based on their thermodynamic characterization. J. Alloys Compd. 2008, 462, 119-124. [CrossRef]

11. Fernández, I.G.; Meyer, G.; Gennari, F. Hydriding/dehydriding behavior of $\mathrm{Mg}_{2} \mathrm{CoH}_{5}$ produced by reactive mechanical milling. J. Alloys Compd. 2008, 464, 111-117. [CrossRef]

12. Gennari, F.; Castro, F. Formation, composition and stability of Mg-Co compounds. J. Alloys Compd. 2005, 396, 182-192. [CrossRef]

13. Chen, J.; Takeshita, H.T.; Chartouni, D.; Kuriyama, N.; Sakai, T. Synthesis and characterization of nanocrystalline $\mathrm{Mg}_{2} \mathrm{CoH}_{5}$ obtained by mechanical alloying. J. Mater. Sci. 2001, 36, 5829-5834. [CrossRef]

14. Berube, V.; Radtke, G.; Dresselhaus, M.; Chen, G. Size effects on the hydrogen storage properties of nanostructured metal hydrides: A review. Int. J. Energy Res. 2007, 31, 637-663. [CrossRef]

15. Berlouis, L.; Cabrera, E.; Hall-Barientos, E.; Hall, P.J.; Dodd, S.B.; Morris, S.; Imam, M.A. Thermal analysis investigation of hydriding properties of nanocrystalline $\mathrm{Mg}-\mathrm{Ni}-$ and $\mathrm{Mg}-\mathrm{Fe}-$ based alloys prepared by high-energy ball milling. J. Mater. Res. 2001, 16, 45-57. [CrossRef]

16. Mezzavilla, S.; Zanella, C.; Aravind, P.R.; Della Volpe, C.; Soraru, G.D. Carbon xerogels as electrodes for supercapacitors. The influence of the catalyst concentration on the microstructure and on the electrochemical properties. J. Mater. Sci. 2012, 47, 7175-7180. [CrossRef]

17. Chen, S.-M.; Ramachandran, R.; Mani, V.; Saraswathi, R. Recent advancements in electrode materials for the high-performance electrochemical supercapacitors: A review. Int. J. Electrochem. Sci. 2014, 9, 4072-4085.

18. Zaid, K.; Suriani, A.B. A review on electrode materials used in capacitive deionization processes for water treatment applications. Sci. Int. 2017, 29, e289.

19. ElKhatat, A.M.; Al-Muhtaseb, S.A. Advances in Tailoring Resorcinol-Formaldehyde Organic and Carbon Gels. Adv. Mater. 2011, 23, 2887-2903. [CrossRef]

20. Yan, M.-F.; Zhang, L.-H.; He, R.; Liu, Z.-F. Synthesis and characterization of carbon aerogels with different catalysts. J. Porous Mater. 2015, 22, 699-703. [CrossRef]

21. Liang, C.; Sha, G.; Guo, S. Resorcinol-formaldehyde aerogels prepared by supercritical acetone drying. J. Non-Crystal. Solids 2000, 271, 167-170. [CrossRef] 
22. Yamamoto, T.; Nishimura, T.; Suzuki, T.; Tamon, H. Control of mesoporosity of carbon gels prepared by sol-gel polycondensation and freeze drying. J. Non-Crystal. Solids 2001, 288, 46-55. [CrossRef]

23. Durairaj, R.B. Resorcinol: Chemistry, Technology and Applications; Springer: Berlin/Heidelberg, Germany, 2005.

24. Ghaani, M.R.; Catti, M. Investigation on the kinetic mechanism of the reduction of $\mathrm{Fe}_{2} \mathrm{O}_{3} / \mathrm{CoO}$-decorated carbon xerogels: A non-isothermal study. J. Solid State Chem. 2019, 277, 368-375. [CrossRef]

25. Herklotz, M.; Scheiba, F.; Hinterstein, M.; Nikolowski, K.; Knapp, M.; Dippel, A.-C.; Giebeler, L.; Eckert, J.; Ehrenberg, H. Advances inin situpowder diffraction of battery materials: A case study of the new beamline P02.1 at DESY, Hamburg. J. Appl. Crystallogr. 2013, 46, 1117-1127. [CrossRef]

26. Jensen, T.R.; Nielsen, T.K.; Filinchuk, Y.; Jørgensen, J.-E.; Cerenius, Y.; Gray, E.M.; Webb, C.J. Versatile in situ powder X-ray diffraction cells for solid-gas investigations. J. Appl. Crystallogr. 2010, 43, 1456-1463. [CrossRef] [PubMed]

27. Nielsen, T.K.; Besenbacher, F.; Jensen, T.R. Nanoconfined hydrides for energy storage. Nanoscale 2011, 3, 2086. [CrossRef]

28. Gutowska, A.; Li, L.; Shin, Y.; Wang, C.M.; Li, X.S.; Linehan, J.C.; Smith, R.S.; Kay, B.D.; Schmid, B.; Shaw, W.J.; et al. Nanoscaffold Mediates Hydrogen Release and the Reactivity of Ammonia Borane. Angew. Chem. Int. Ed. 2005, 44, 3578-3582. [CrossRef]

29. Peng, D.; Ding, Z.; Zhang, L.; Fu, Y.; Wang, J.; Li, Y.; Han, S. Remarkable hydrogen storage properties and mechanisms of the shell-core MgH2@carbon aerogel microspheres. Int. J. Hydrogen Energy 2018, 43, 3731-3740. [CrossRef]

30. Contreras, M.S.; Paez, C.; Zubizarreta, L.; Léonard, A.; Blacher, S.; Olivera-Fuentes, C.G.; Arenillas, A.; Pirard, J.-P.; Job, N. A comparison of physical activation of carbon xerogels with carbon dioxide with chemical activation using hydroxides. Carbon 2010, 48, 3157-3168. [CrossRef]

31. Fricke, J.; Tillotson, T. Aerogels: Production, characterization, and applications. Thin Solid Films 1997, 297, 212-223. [CrossRef]

32. Morozkin, A.V. Gd-Co-Ge system at 870/1070 K. Intermetallics 2012, 25, 136-138. [CrossRef]

33. Singh, M.; Barkei, M.; Inden, G.; Bhan, S. High-temperature X-ray diffraction study on $\mathrm{Co}_{75} \mathrm{Sn}_{25}$ alloy. Phys. Status Solidi 1985, 87, 165-168. [CrossRef]

34. Huot, J.; Hayakawa, H.; Akiba, E. Preparation of the hydrides $\mathrm{Mg}_{2} \mathrm{FeH}_{6}$ and $\mathrm{Mg}_{2} \mathrm{CoH}_{5}$ by mechanical alloying followed by sintering. J. Alloys Compd. 1997, 248, 164-167. [CrossRef]

35. Norek, M.; Nielsen, T.; Polanski, M.; Kunce, I.; Płociński, T.; Jaroszewicz, L.R.; Cerenius, Y.; Jensen, T.R.; Bystrzycki, J. Synthesis and decomposition mechanisms of ternary $\mathrm{Mg}_{2} \mathrm{CoH}_{5}$ studied using in situ synchrotron X-ray diffraction. Int. J. Hydrogen Energy 2011, 36, 10760-10770. [CrossRef]

36. Ghaani, M.R.; English, N.J. Hydrogen-/propane-hydrate decomposition: Thermodynamic and kinetic analysis. Mol. Phys. 2019, 117, 2434-2442. [CrossRef]

37. Dev, P.; Agrawal, S.; English, N.J. Functional Assessment for Predicting Charge-Transfer Excitations of Dyes in Complexed State: A Study of Triphenylamine-Donor Dyes on Titania for Dye-Sensitized Solar Cells. J. Phys. Chem. A 2013, 117, 2114-2124. [CrossRef]

38. Solomentsev, G.Y.; English, N.J.; Mooney, D.A. Hydrogen bond perturbation in hen egg white lysozyme by external electromagnetic fields: A nonequilibrium molecular dynamics study. J. Chem. Phys. 2010, 133, 235102. [CrossRef]

(C) 2020 by the authors. Licensee MDPI, Basel, Switzerland. This article is an open access article distributed under the terms and conditions of the Creative Commons Attribution (CC BY) license (http://creativecommons.org/licenses/by/4.0/). 